Article

\title{
Quantum Chemical Study on the Influence of Dodecyl Trimethyl Ammonium Bromide on the $\mathrm{CH}_{4}$ Adsorption of Coal
}

\author{
Shuo Liu ${ }^{1} \mathbb{D}$, Jiaxing Gao ${ }^{2}$, Yibo Tang ${ }^{1}$, Junfeng Wang ${ }^{3, *}$ and Shaocheng Ge ${ }^{1}$ \\ 1 College of Safety and Emergency Management Engineering, Taiyuan University of Technology, \\ Taiyuan 030024, China; liushuo89123@163.com (S.L.); tangyibo11@126.com (Y.T.); \\ geshaocheng@163.com (S.G.) \\ 2 School of Emergency Management and Safety Engineering, China University of Mining \\ and Technology (Beijing), Beijing 100083, China; bqt1800102038@student.cumtb.edu.cn \\ 3 College of Mining and Technology, Taiyuan University of Technology, Taiyuan 030024, China \\ * Correspondence: wangjunfeng@tyut.edu.cn; Tel.: +86-351-6066518
}

Received: 26 May 2020; Accepted: 21 July 2020; Published: 26 July 2020

check for updates

\begin{abstract}
The adsorption of dodecyl trimethyl ammonium bromide (DTAB) on coal can affect the wettability of coal and change the water absorption of coal. After DTAB treatment, the change in the $\mathrm{CH}_{4}$ adsorption capacity of coal is worth further study. To reveal the microscopic mechanism of the influence of DTAB on the $\mathrm{CH}_{4}$ adsorption capacity of coal, we employed the density functional theory (DFT) with the 6-311 G (d,p) basis set. DFT-based computations interpreted the adsorption process of $\mathrm{CH}_{4}$ and DTAB on coal molecules and determined the stable structure, adsorption distance, Mulliken overlapping populations, and adsorption energies of the two adsorption configurations. The results showed that the adsorption energies of $\mathrm{CH}_{4}$ and DTAB on the molecular model of coal were 2.15 and $42.69 \mathrm{~kJ} / \mathrm{mol}$ and the adsorption stability distances were 0.261 and $0.238 \mathrm{~nm}$, respectively. The DTAB-coal configuration was more stable than the $\mathrm{CH}_{4}$-coal configuration. When there was competitive adsorption between DTAB and $\mathrm{CH}_{4}$ on coal, the coal molecules preferentially adsorb the DTAB. Infrared spectroscopy and adsorption experiments were also carried out, and the calculation results of quantum chemistry are consistent with the experimental results.
\end{abstract}

Keywords: $\mathrm{CH}_{4}$ adsorption; quantum chemistry; density functional theory; adsorption energies

\section{Introduction}

Underground methane hazards are very dangerous, due to their flammability and explosibility [1-3]. An increase in mining depth has led to a rise in ground stress and gas pressure. Gas disasters, especially coal and gas outbursts, are becoming more serious [4]. It should also be stressed that methane is one of the most harmful greenhouse gases and constitutes a major risk to the natural environment [5].

The permeability of a coal seam can be enhanced through various forms of coal seam fracturing technology in coal mining sites, to improve the gas extraction effect [6,7]. Recently, a waterjet cutting technique was tested in Australia. The waterjet cutting technique involved the integration of pure waterjet drilling technology with conventional directional drilling techniques [8]. The hydro-fracturing technique is another pre-drainage method that has been successfully used in the USA. This method is not universally applicable due to the different geology, coal seam characteristics, in-situ gas content, pressure, and saturation, as well as gas sources and the surrounding strata's low in-situ permeability [9]. In this study, we aimed to change the methane adsorption characteristic of coal seams by adding appropriate additives to fracturing fluids, to improve the efficiency of methane extraction. 
Due to the suitable pore structure, large specific surface area, and residual charges on the molecular surface, coal has a high adsorption capacity for $\mathrm{CH}_{4}$ and other gases [10,11]. According to previous research [12-14], the coal surface shows weak or neutral electrical properties at the macroscale. However, it has specific electrical characteristics at the nanoscale. With the increase of the coal ranks, the negative potential of the coal experienced a trend of slight decrease and then rapid increase. Wang et al. [15] confirmed that the surface charge of coal is negative in the water system.

Quaternary ammonium surfactants are a kind of cationic surfactant, which can adsorb well on the surface of coal molecules, thus changing the physical properties of coal. Quaternary ammonium surfactants are quaternary ammonium salts with a long chain of alkyl groups $[16,17]$. The quaternary ammonium salt side of the molecule is hydrophilic, whereas the alkyl group side is hydrophobic. This special structure reduces the surface tension of the oil-water interface, change the wettability of rock layers and improving the oil displacement efficiency [18]. Therefore, quaternary ammonium surfactants are widely used in the petrochemical industry. When a quaternary ammonium salt surfactant adsorbs to the coal surface, the quaternary ammonium salt side forms a directional and tight adsorption layer on the coal surface, making the alkyl group far away from the coal surface. This kind of adsorption can reduce the hydrophilicity of the coal and inhibit the water reabsorption after drying [19-21]. Quaternary ammonium salt surfactants are commonly used in the coal washing stage [22]. The influence of surfactant treatment on the $\mathrm{CH}_{4}$ adsorption capacity of coal still needs exploring.

Dodecyl trimethyl ammonium bromide (DTAB) is a surfactant commonly used in petroleum production as a wetting reversal agent [23]. The adsorption process of $\mathrm{CH}_{4}$ and DTAB on the surface of the coal molecular model was studied by using the density functional theory to reveal the influence of DTAB on the $\mathrm{CH}_{4}$ adsorption capacity of coal. The parameters of optimized structure, electronic static potential (ESP), adsorption distance, Mulliken overlap population, and adsorption energies of the two adsorption configurations were obtained by calculation. The microscopic mechanism of the influence of DTAB on the $\mathrm{CH}_{4}$ adsorption of coal was analyzed. The predicted properties were compared to an experiment where the available and reasonable agreement was found. This work provides new thoughts for further exploring the study of fracturing for $\mathrm{CH}_{4}$ stimulation and preventing $\mathrm{CH}_{4}$ reabsorption in a coal seam.

\section{Methods}

\subsection{Calculation Method}

Density functional theory (DFT) with the B3LYP-D3 functional and 6-311 G $(\mathrm{d}, \mathrm{p})$ as the basis set was selected based on its combination of relative accuracy and speed. This theory was used to optimize the geometries of molecules of $\mathrm{CH}_{4}, \mathrm{DTAB}$, and coal. Then, the ESP of the molecules was calculated to analyze possible adsorption sites. The adsorption configurations of $\mathrm{CH}_{4}-\mathrm{coal}$ and DTAB-coal were optimized based on the optimal adsorption sites. When $\mathrm{CH}_{4}$ or DTAB adsorbed to the surface of coal molecules, the total energy of the system would be reduced. The more energy reduced, the more stable the adsorption structure would be. The Mulliken overlapping population, adsorption distance, and adsorption energies of $\mathrm{CH}_{4}-\mathrm{coal}$ and DTAB-coal adsorption configurations were obtained, respectively $[24,25]$. This information was the theoretical basis for analyzing which adsorption model was more stable.

\subsection{Calculation Model}

Coal is composed of aromatic rings, side chains, and bridge bonds [26-28]. The structure model of coal was deduced and hypothesized based on various structural parameters of coal, which were used to represent the molecular diagram of the average coal structure. Wiser proposed the Wiser model [29], which is a widely accepted and relatively comprehensive and reasonable coal chemical structure model. This model already possesses most of the concepts of modern coal structure [30,31]. 
The model contains aromatic structures with up to 5 rings. The aromatic rings are connected by weak bonds, such as aliphatic bridge bonds, ether bonds, and sulfur ether bonds. There are also hydroxyl, carbonyl, mercaptan, and thiophene groups on the edges of the aromatic rings. Elements such as oxygen, sulfur, and nitrogen exist as heterocycles.

Calculation will consume too many computing resources when it comes to quantum mechanical calculations for complex molecules. Using the chemical base unit as the model material can achieve a balance between computational efficiency and computational reliability. According to Marzec [32], the organic matter of coal consists of macromolecules that contain aromatic and hydroaromatic rings linked by aliphatic bridges. $\mathrm{O}, \mathrm{N}$, and $\mathrm{S}$ heteroatoms occur in furan, quinone, pyridine, pyrrole, and thiophene rings, as well as some other functional groups. The model used in this study was taken from a part of the Wiser model, as shown in Figure 1. This coal molecular model retains the typical characteristic structure of coal molecules. The model consists of structures such as aromatics, nitrogen heterocyclic rings, aliphatic bridge bonds, oxygen-containing functional group side chains $(-\mathrm{OH})$, sulfur-containing side chains, and methyl side chains. The simplified model not only retained the characteristic structure of the Wiser model, but also guaranteed computational efficiency.

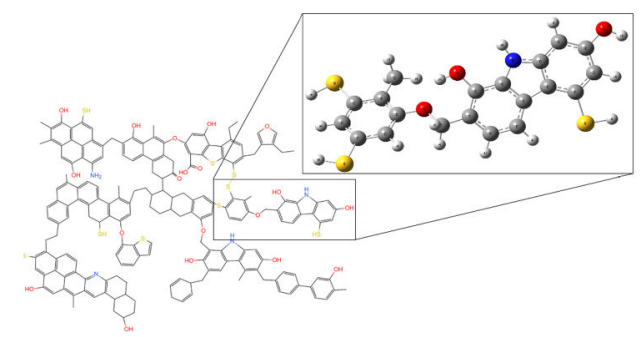

Figure 1. A simplified model for quantum chemistry computing of the coal molecule.

\subsection{FTIR Study Method}

The coal sample for verification was selected from Coal Seam No. 3, Chengzhuang Coal Mine, Shanxi, China. The fresh coal was first collected from Chengzhuang Coal Mine and crushed using a crusher, then sieved to 60-120 meshes. The sieved coal sample was then immersed in the DTAB solution ( $1 \%$ by mass) for $24 \mathrm{~h}$. Finally, the soaked coal sample was dried in a vacuum drying oven in an oxygen-free environment for further use.

The experiments were carried out using Fourier-transform infrared spectroscopy (FTIR) (MIRacle 10 SHIMADZU; Kyoto, JPN). FTIR can acquire the changes in functional groups of the coal molecules after DTAB treatment. The test condition was set as follows: the range of scanning wavenumbers was from 400 to $4000 \mathrm{~cm}^{-1}$, the resolution was $4 \mathrm{~cm}^{-1}$; the number of scans was 64 .

\subsection{Methane Adsorption Experiment}

The adsorption capabilities of methane of coal samples, before and after the DTAB treatment, were measured using the high-pressure volumetric method. This experiment directly investigated the influence of DTAB treatment on the methane adsorption capacity of coal samples. During the experiments, the adsorption capacity, dissociation capacity, and desorption capacity of coal were calculated according to the MT/T752-1997 (China Department of Coal Industry, Beijing, China 1997).

\section{Results and Discussion}

\subsection{The ESP Analyses}

The van der Waals forces between adsorbates and adsorbents are mainly composed of induction, dispersion, and orientation forces. Scholars generally believe that coal can absorb a large number of gases due to the existence of the residual electric field on the coal surface [33,34]. Methane molecules 
were adsorbed on the coal molecular model by the residual electric field [35]. During the adsorption process, methane molecules are polarized, and their bonds are stretched. The analysis of the ESP of the adsorbate (coal) and adsorbents $\left(\mathrm{CH}_{4}\right.$ and DTAB) was of considerable significance to estimate the possible adsorption sites and calculate the adsorption parameters.

The ESPs of $\mathrm{CH}_{4}, \mathrm{DTAB}$, and the coal molecular model are shown in Figures 2-4. The methane molecule is a regular tetrahedral structure with four hydrogen atoms at the vertices. The carbon atom is located at the center of the regular tetrahedron. For the $\mathrm{C}-\mathrm{H}$ bond, the carbon atom has a more exceptional ability to attract electrons than hydrogen. The hydrogen atoms surrounding the methane molecule were positively charged, with a maximum value of $7.73 \times 10^{-3}$ a.u.

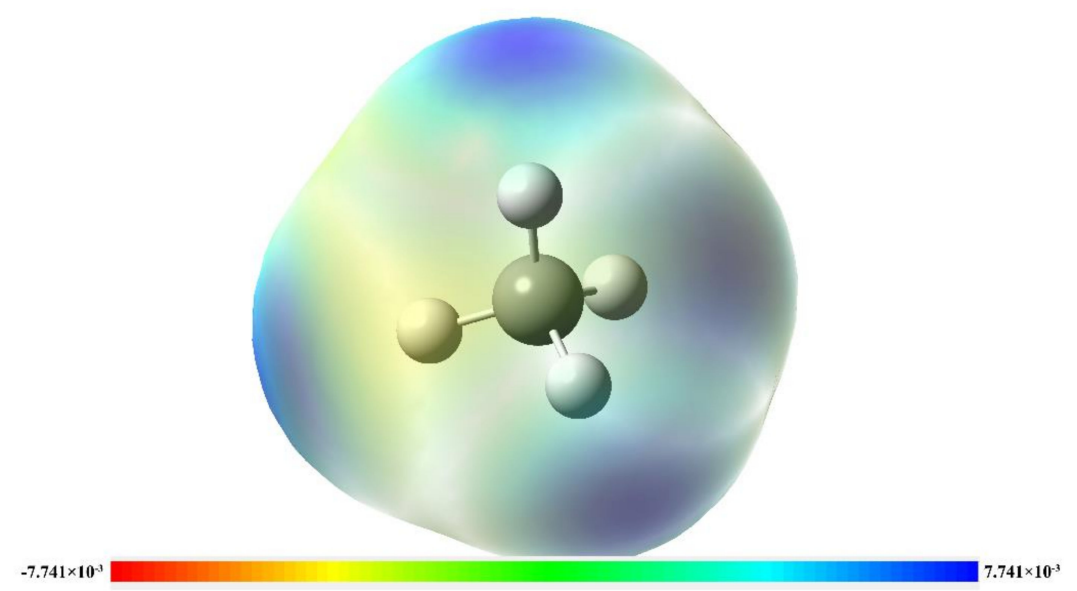

Figure 2. Electrostatic potential distribution of $\mathrm{CH}_{4}$.

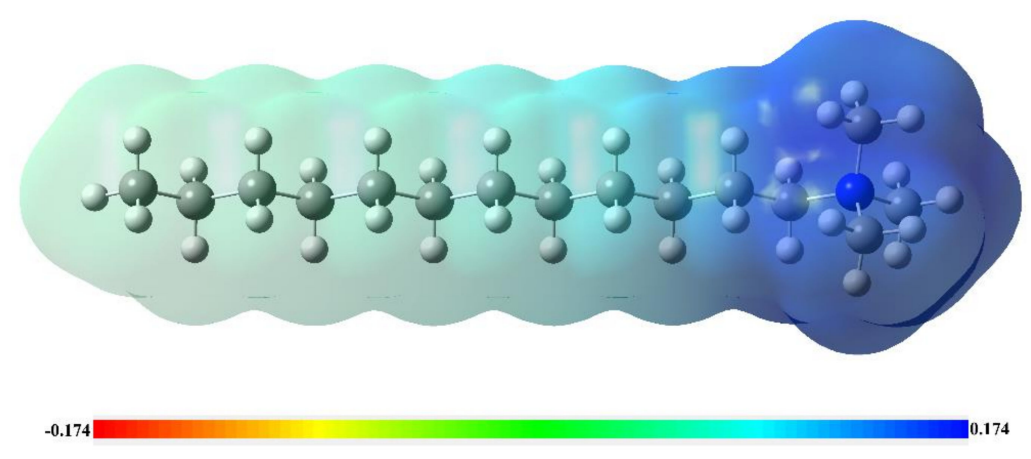

Figure 3. Electrostatic potential distribution of DTAB+.

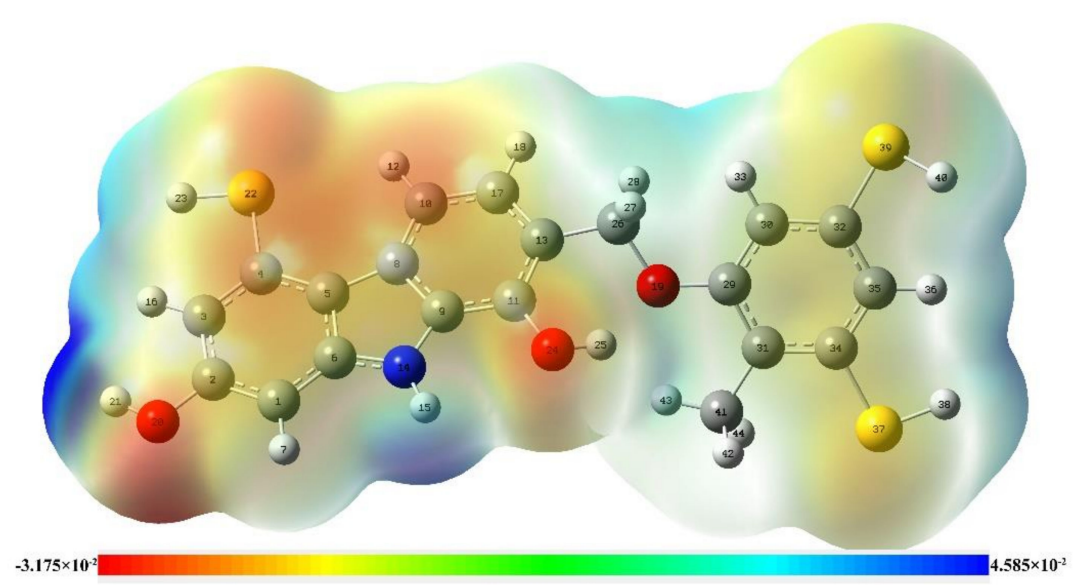

Figure 4. Electrostatic potential distribution of coal. 
The hydrolysis of DTAB produced the quaternary ammonium cation, which showed significant positive potential with a maximum value of $1.73 \times 10^{-1} \mathrm{a}$.u. The positive potential on the surface of the quaternary ammonium cation was higher than that of the $\mathrm{CH}_{4}$ molecule.

There were both positive and negative potential distributions on the coal molecular model. The negative potential positions were located near the aromatic rings and the side chains of the hydroxyl and sulfhydryl groups. The maximum value of the negative potential was located near O20, and its value was $3.14 \times 10^{-2}$ a.u. The positive potential positions on the coal molecular model were mainly located near the $\mathrm{H}$ atoms, especially at $\mathrm{O}-\mathrm{H}$ and $\mathrm{N}-\mathrm{H}$.

According to the ESP distribution of the coal molecular structure, the adsorption sites of $\mathrm{CH}_{4}$ and DTAB were found near the aromatic rings and the side chains of the hydroxyl and sulfhydryl groups of the coal molecular model. This conclusion was consistent with previous research conclusions. The adsorption sites and the corresponding ESP distributions are shown in Table 1. According to the ESP values of these potential adsorption sites, the optimal adsorption site is near the $\mathrm{O} 20 \mathrm{atom}$. To investigate the effect of DTAB on the interaction of $\mathrm{CH}_{4}$ with the coal, the Mulliken overlapping layout and adsorption energies during the adsorption processes of $\mathrm{CH}_{4}$-coal and DTAB-coal configurations were calculated. The microscopic mechanism of the influence of DTAB on the $\mathrm{CH}_{4}$ adsorption of coal was analyzed. The optimized adsorption geometries for the $\mathrm{CH}_{4}$-coal and DTAB-coal configurations are shown in the Figures 5 and 6, respectively.

Table 1. Electric potentials of adsorption sites on coal molecules.

\begin{tabular}{ccc}
\hline No. & Adsorption & $\begin{array}{c}\text { Electric Potentials } \\
\text { (a.u.) }\end{array}$ \\
\hline $1 \#$ & O20 & $-3.14 \times 10^{-2}$ \\
$2 \#$ & C8-C10 & $-2.61 \times 10^{-2}$ \\
$3 \#$ & O24 & $-2.61 \times 10^{-2}$ \\
$4 \#$ & S22 & $-2.55 \times 10^{-2}$ \\
$5 \#$ & C4-C5 & $-2.38 \times 10^{-2}$ \\
$6 \#$ & S39 & $-2.06 \times 10^{-2}$ \\
$7 \#$ & S37 & $-1.78 \times 10^{-2}$ \\
\hline
\end{tabular}

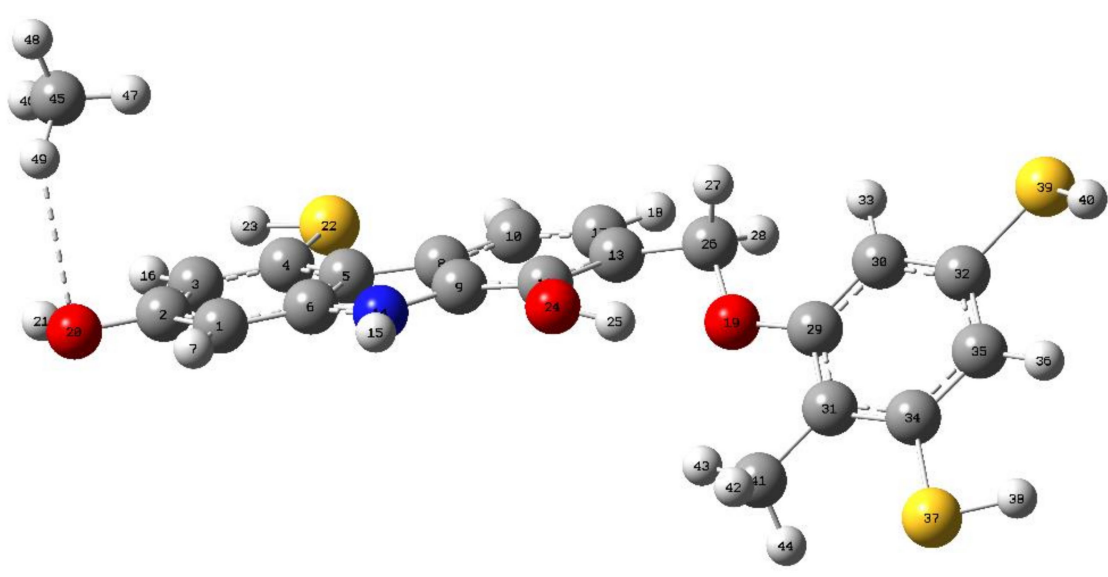

Figure 5. Optimized geometries of the $\mathrm{CH}_{4}$-coal configuration. 


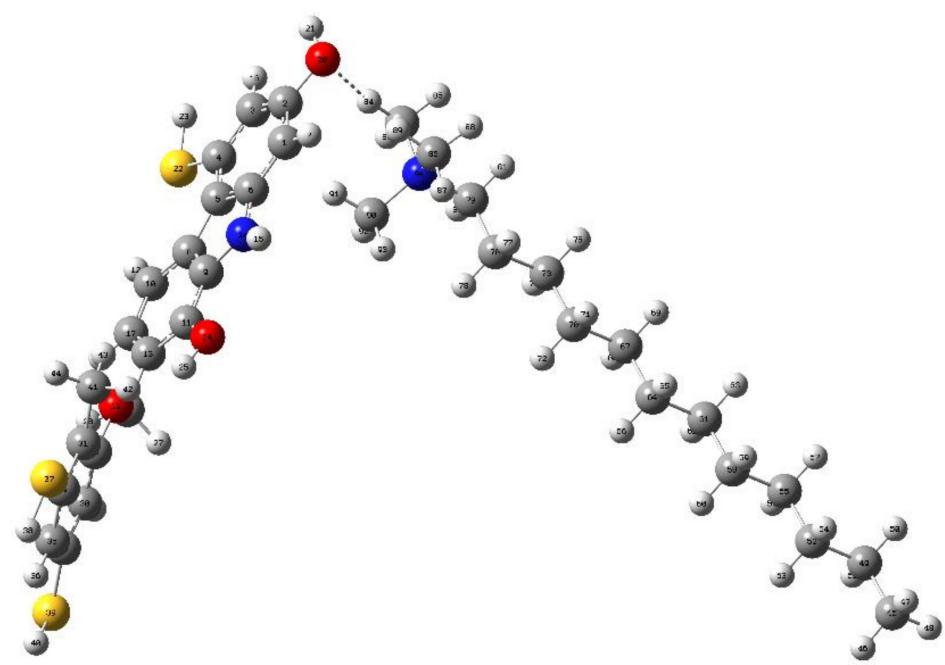

Figure 6. Optimized geometries of the DTAB-coal configuration.

The bond angles of the methane molecule before and after adsorption can be obtained from the optimized structure, as shown in Table 2. The bond angles of the $\mathrm{H}-\mathrm{C}-\mathrm{H}$ in $\mathrm{CH}_{4}$ before adsorption were all $109.47^{\circ}$. After adsorption, the angles of the $\mathrm{H}-\mathrm{C}-\mathrm{H}$ were different. The structure of the $\mathrm{CH}_{4}$ molecule changed from a regular tetrahedron to a rectangular pyramid during the adsorption process, and the dipole moment of the molecule changed from 0 to $2.9 \times 10^{-3}$ debye, which was more conducive to the adsorption.

Table 2. Bond angles of the methane molecule before and after adsorption.

\begin{tabular}{|c|c|c|c|c|c|}
\hline & $\begin{array}{c}A(48,45,47) \\
\left({ }^{\circ}\right)\end{array}$ & $\begin{array}{c}A(48,45,49) \\
\left({ }^{\circ}\right)\end{array}$ & $\begin{array}{c}A(48,45,46) \\
\left(^{\circ}\right)\end{array}$ & $\begin{array}{c}A(47,45,49) \\
\left({ }^{\circ}\right)\end{array}$ & $\begin{array}{c}\text { Dipole Moment } \\
\text { (Debye) }\end{array}$ \\
\hline Before Adsorption & 109.47 & 109.47 & 109.47 & 109.47 & 0 \\
\hline After adsorption & 109.86 & 109.60 & 109.22 & 108.93 & $2.9 \times 10^{-3}$ \\
\hline
\end{tabular}

\subsection{Mulliken Overlapping Population}

Mulliken's population analysis is a method of charting the distribution of electron charge to atoms, atomic orbitals, and chemical bonds in molecules. This method converts the wave function, obtained from molecular orbital theory, into intuitive chemical information to be able to study electron transfer, molecular polarity, and chemical bond type and strength [36]. The number of overlapping electron charges distributed between two atoms is called the Mulliken overlapping population. The Mulliken overlapping population determines the bonding characteristics of molecular orbitals and the strength of chemical bonds between atoms. The larger the Mulliken overlapping population, the stronger the interaction between the two atoms [37]. In this study, the interaction between adsorbent and adsorbate was analyzed using Mulliken's population analysis. The adsorption bond distances and Mulliken overlapping populations of $\mathrm{CH}_{4}-\mathrm{coal}$ and DTAB-coal configurations are documented in Table 3.

Table 3. Calculated adsorption bond distances $(\mathrm{nm})$ and Mulliken overlapping populations for the adsorption of the $\mathrm{CH} 4$ and DTAB molecules on coal.

\begin{tabular}{cccc}
\hline $\begin{array}{c}\text { Adsorption } \\
\text { Configurations }\end{array}$ & Bond & $\begin{array}{c}\text { Adsorption Bond } \\
\text { Distances }(\text { nm })\end{array}$ & $\begin{array}{c}\text { Mulliken Overlapping } \\
\text { Populations }\end{array}$ \\
\hline $\mathrm{CH}_{4}-\mathrm{coal}$ & $\mathrm{O} 20-\mathrm{H} 49$ & 0.262 & 0.063 \\
$\mathrm{DTAB}-\mathrm{coal}$ & $\mathrm{O} 20-\mathrm{H} 84$ & 0.237 & 0.131 \\
\hline
\end{tabular}


The nearest distances between adsorbent and adsorbate were found to be 0.262 and $0.237 \mathrm{~nm}$ for $\mathrm{CH}_{4}$-coal and DTAB-coal configurations, respectively. The distance in the DTAB-coal configuration was noticeably shorter compared to that of the $\mathrm{CH}_{4}$-coal configuration. In the $\mathrm{CH}_{4}-$ coal configuration, the Mulliken overlapping population of adsorption site O20-H49 was 0.063, whereas the value at adsorption site O20-H84 was 0.131 in the DTAB-coal configuration. The larger the Mulliken overlapping population, the stronger the interaction between the two atoms, and as such, it can be inferred that the adsorption of DTAB on the surface of the coal molecular model was stronger than that of $\mathrm{CH}_{4}$.

\subsection{Adsorption Energies}

When the adsorbate adsorbs the adsorbent, the total energy of the system is reduced. The higher the adsorption energy, the more stable the adsorption. The adsorption energy is defined in Equation (1)

$$
\Delta E=E_{\text {system }}-E_{\text {adsorbent }}-E_{\text {adsorbate }}
$$

where $\Delta E$ denotes adsorption energy, $E_{\text {system }}$ denotes the total energy of the system after adsorption, $E_{\text {adsorbent }}$ denotes the energy of the adsorbent, and $E_{\text {adsorbate }}$ denotes the energy of the adsorbate.

We obtained the adsorption energies of the two adsorption configurations by quantum chemical calculations. The calculated adsorption energies are shown in Table 4. The adsorption energy of the DTAB-coal configuration was much higher $(78.77 \mathrm{~kJ} / \mathrm{mol})$ than that of $\mathrm{CH}_{4}-$ coal configuration $(26.26$ $\mathrm{kJ} / \mathrm{mol}$ ). The comparison of the adsorption energies clearly showed that the DTAB-coal configuration was more stable than the $\mathrm{CH}_{4}$-coal configuration. According to the literature, the adsorption energy of physical adsorption is less than $30 \mathrm{~kJ} / \mathrm{mol}$, and the adsorption energy of chemical adsorption is within the range of $50-960 \mathrm{~kJ} / \mathrm{mol}$. It can be concluded that the adsorption of $\mathrm{CH}_{4}$ on coal is physical adsorption, whereas the adsorption of DTAB on coal is chemical. The analysis results were consistent with previous research conclusions [38,39].

Table 4. Calculated adsorption energies for the adsorption of $\mathrm{CH}_{4}$ and DTAB molecules on coal.

\begin{tabular}{|c|c|c|c|c|}
\hline \multirow{2}{*}{$\begin{array}{l}\text { Adsorption } \\
\text { Configurations }\end{array}$} & \multicolumn{2}{|c|}{$\begin{array}{l}\text { System Energy Before Adsorption } \\
\text { (Hartree) }\end{array}$} & \multirow{2}{*}{$\begin{array}{c}\text { System Energy } \\
\text { After Adsorption } \\
\text { (Hartree) }\end{array}$} & \multirow{2}{*}{$\begin{array}{c}\text { Adsorption } \\
\text { Energies } \\
(\mathrm{kJ} / \mathrm{mol})\end{array}$} \\
\hline & Coal & Adsorbate & & \\
\hline $\mathrm{CH}_{4}-\mathrm{coal}$ & -2247.76 & -40.53 & -2288.30 & 26.26 \\
\hline DTAB-coal & -2247.76 & -646.84 & -2894.63 & 78.77 \\
\hline
\end{tabular}

Through quantum chemical calculation, the adsorption distance, Mulliken overlapping populations, and adsorption energies of $\mathrm{CH}_{4}$ and DTAB on the coal molecular model were obtained, respectively. These data suggested an overall stronger interaction in the DTAB-coal configuration than in the $\mathrm{CH}_{4}$-coal configuration. When there was competitive adsorption between DTAB and $\mathrm{CH}_{4}$ on the coal surface, the coal preferentially adsorbed DTAB to reach a stable state. The coal sample after DTAB treatment reduced its ability to adsorb $\mathrm{CH}_{4}$.

\subsection{Experimental Verification}

From Figure 7, it can be seen that the peak height and area of the hydroxyl vibration absorption peak (3747-3000 $\mathrm{cm}^{-1}$ ) of the coal sample after DTAB treatment were significantly reduced, because the adsorption of DTAB near the hydroxyl group of coal inhibited the vibration of hydroxyl. The peak heights and areas of the aromatic ring $(C=C)$, as well as the aldehydes, the ketones, and the esters $(C=O)$ (1773-1511 $\left.\mathrm{cm}^{-1}\right)$ were also reduced. These results indicated that the oxygen-containing functional groups were adsorption sites of DTAB as well. The method of peak fitting was adopted to analyze the positions of each vibration adsorption peak in the overlapped region of the hydroxyl. The results are shown in Figures 8 and 9. 


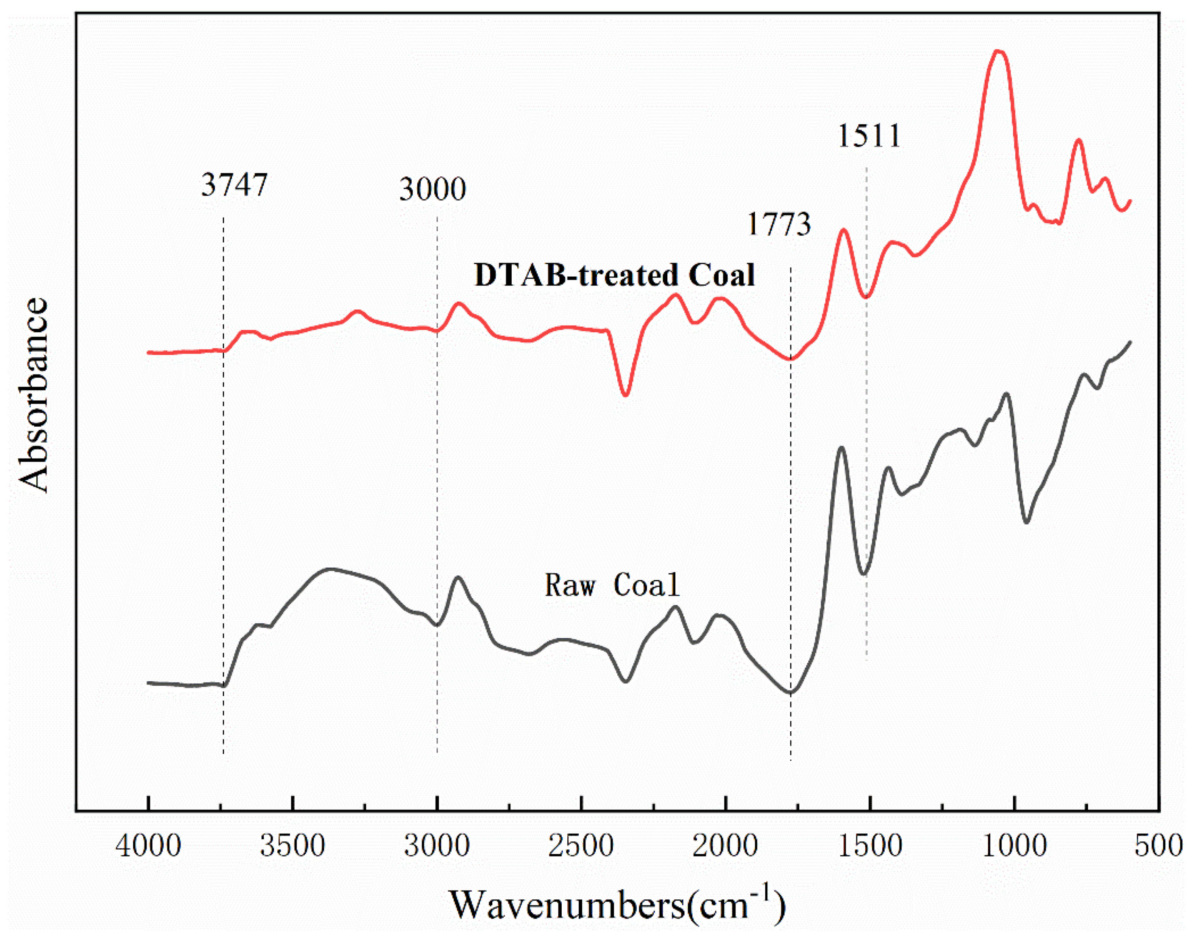

Figure 7. FTIR results of coal samples before and after DTAB treatment.

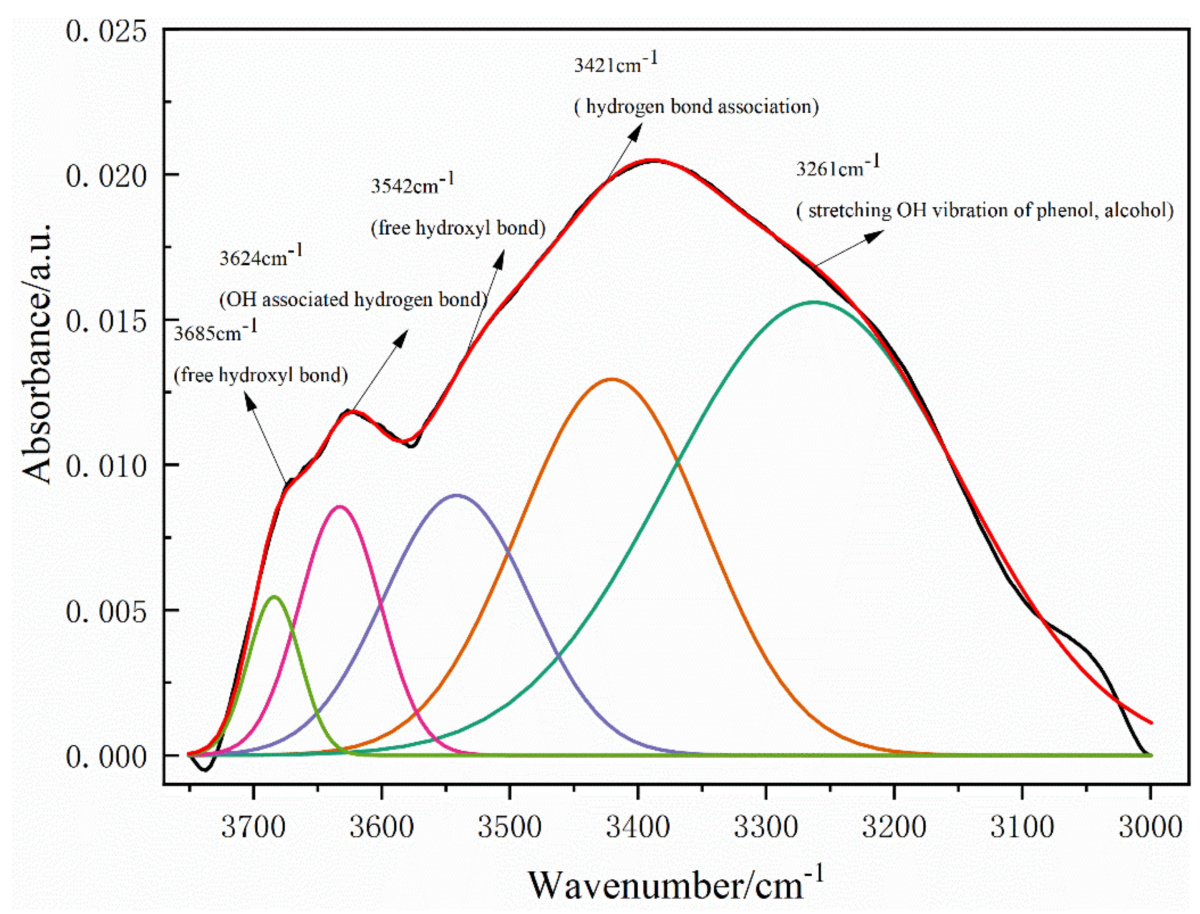

Figure 8. Peak fitting in $3747-3000 \mathrm{~cm}^{-1}$ zone before the DTAB treatment. 


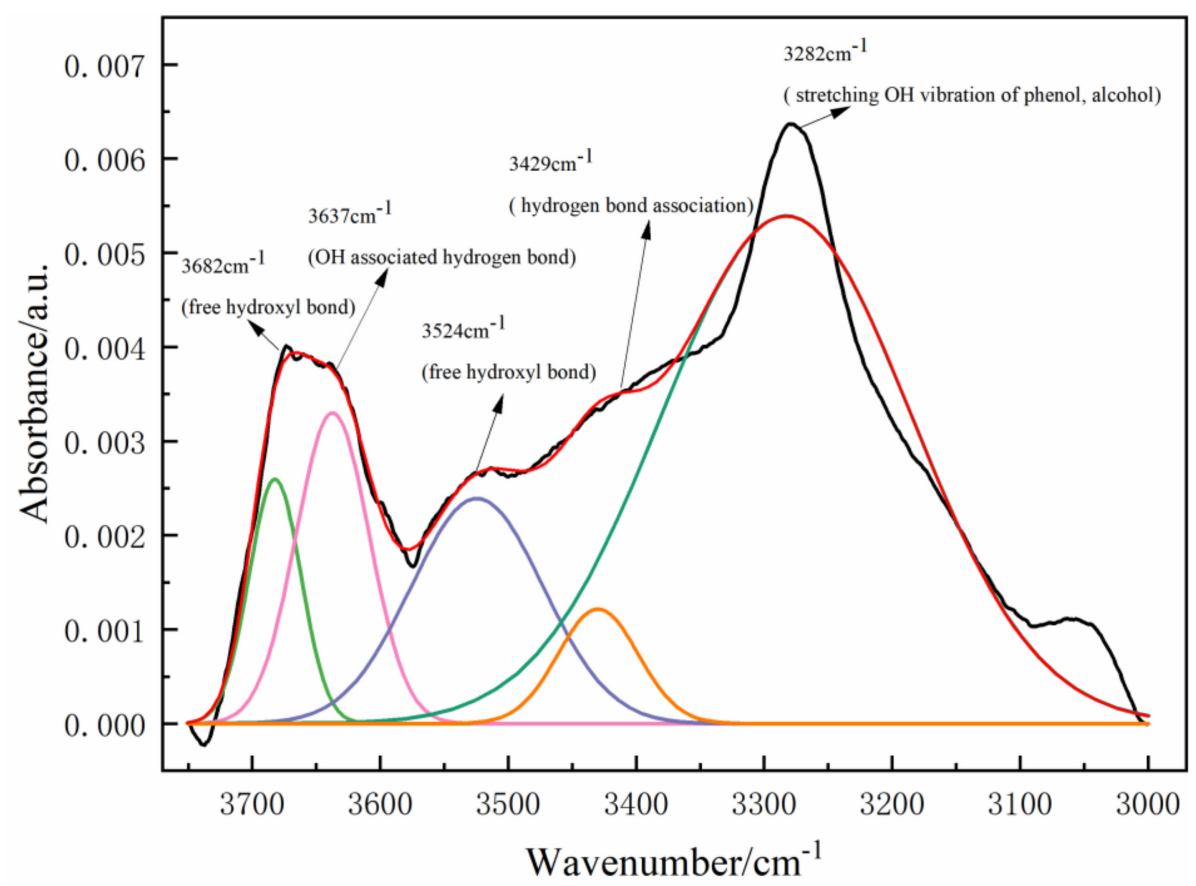

Figure 9. Peak fitting in $3747-3000 \mathrm{~cm}^{-1}$ zone after the DTAB treatment.

The stretching vibration peak of aromatic C-Br exists at $1075-1025 \mathrm{~cm}^{-1}$. The vibration peak was enhanced because of the conjugation between $\mathrm{Br}$ and the aromatic rings. The $\mathrm{Br}$ ions of DTAB can form hydrogen bonds with the aromatic rings, and the $\mathrm{H}$ ions on the aromatic rings were substituted by $\mathrm{Br}$ ions to form the aromatic $\mathrm{C}-\mathrm{Br}$ structure.

The peaks at 1000 and $600 \mathrm{~cm}^{-1}$ represent minerals and ash. By comparing the infrared curves before and after DTAB treatment, we can see that the peaks of minerals and ash become weaker after DTAB treatment. This is because some soluble minerals and ash are taken away by the DTAB solution during immersion.

The hydroxyl vibration zone $\left(3747-3000 \mathrm{~cm}^{-1}\right)$ contains four types of absorption peaks. They are free hydroxyl bonds (around 3697-3542 $\mathrm{cm}^{-1}$ ), OH-associated hydrogen bonds (around 3640-3624 $\mathrm{cm}^{-1}$ ), hydrogen bond associations (around $3400 \mathrm{~cm}^{-1}$ ), and stretching $\mathrm{OH}$ vibrations of phenol and alcohol (3200-3550 $\left.\mathrm{cm}^{-1}\right)$. By comparing the peaks in Figures 8 and 9 Figure 8; Figure 9, we can see these four kinds of peaks were suppressed after the DTAB treatment. The adsorption peaks of the hydrogen bond associations decreased the most, to $3429 \mathrm{~cm}^{-1}$. All of these peak changes indicated that the oxygen-containing functional groups in the coal samples were the adsorption sites of DTAB. It effectively and fully adsorbed the DTAB solution.

The isothermal adsorption curves of $\mathrm{CH}_{4}$ are shown in Figure 10. The adsorption constants of raw coal samples were $48.64894 \mathrm{~m}^{3} / \mathrm{t}$ and $0.60029 \mathrm{MPa}^{-1}$, whereas the adsorption constants of DTAB-treated coal samples were $30.509 \mathrm{~m}^{3} / \mathrm{t}$ and $1.0602 \mathrm{MPa}^{-1}$. After the DTAB treatment, the $\mathrm{CH}_{4}$ adsorption capacity of coal decreased $37.3 \%$, from $48.64894 \mathrm{~m}^{3} / \mathrm{t}$ to $30.509 \mathrm{~m}^{3} / \mathrm{t}$, because the original adsorption position of methane on the coal surface was occupied by DTAB, thus weakening the $\mathrm{CH}_{4}$ adsorption capacity of coal. The experimental results were consistent with the quantum chemical calculation results above. 


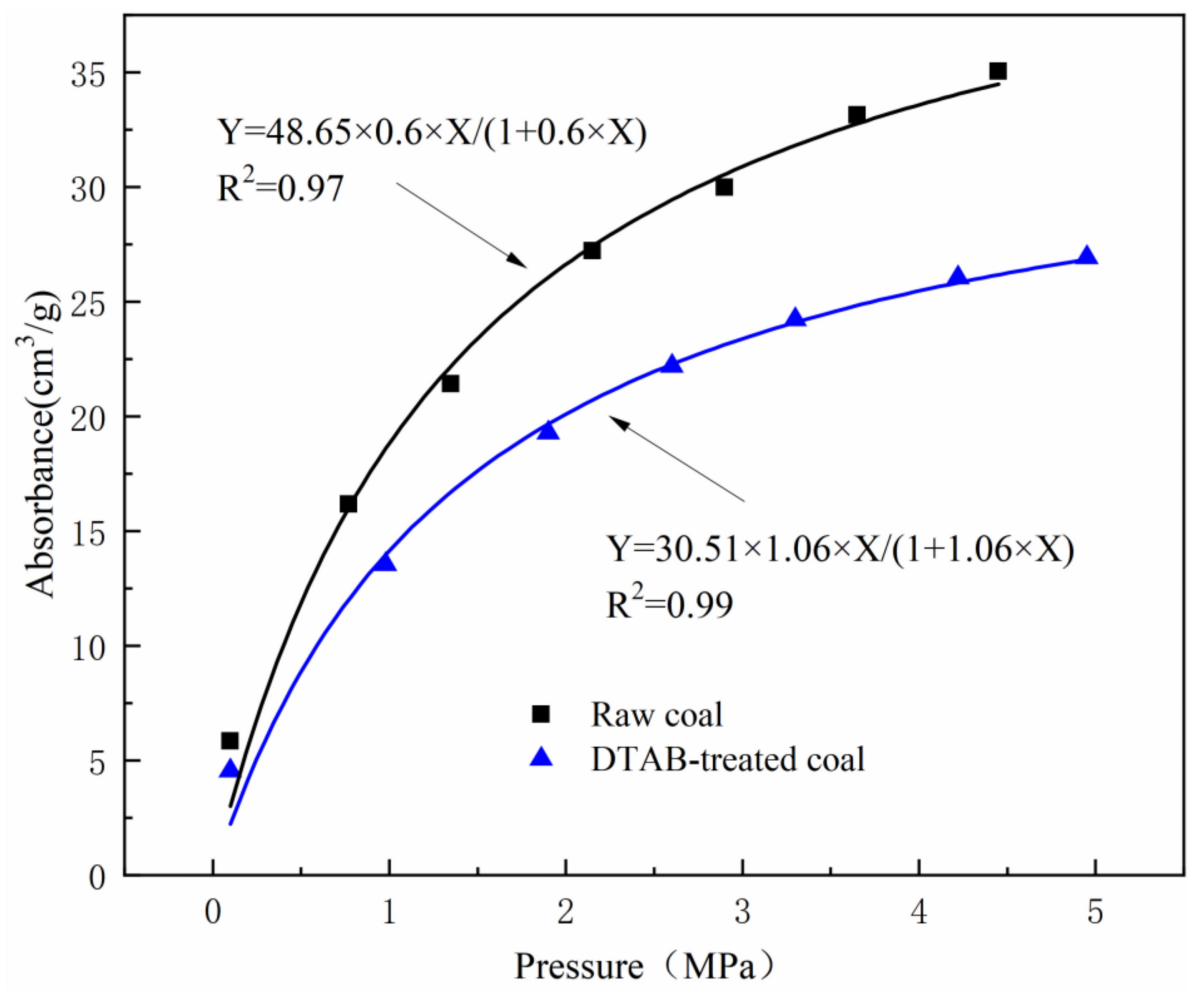

Figure 10. Isothermal adsorption curve of $\mathrm{CH}_{4}$ on coal samples before and after DTAB treatment.

\section{Conclusions}

Underground methane hazards are very dangerous because of their flammability and explosibility. Gas disasters, especially coal and gas outbursts, are becoming more serious due to the increase in mining depth. It is necessary to undertake appropriate measures to ensure safe working conditions.

DTAB is a surfactant commonly used in petroleum processing as a wetting reversal agent. The authors introduced DTAB into the fracturing fluid of coal seam and discussed its effect on the gas adsorption performance of coal. The results of the theoretical calculations and experimental verification showed that DTAB can inhibit the adsorption of $\mathrm{CH}_{4}$ on coal.

The adsorption of $\mathrm{CH}_{4}$ and DTAB on the coal molecular model was investigated by employing density functional theory. The computed ESP results showed that there was some residual charge on the surface of the coal molecular model. The hydrogen atoms on the periphery of the methane molecule and the quaternary ammonium side of the DTAB+ showed a positive charge. They preferentially adsorbed near the oxygen-containing functional groups with strong negative potential on the surface of the coal molecular model. The adsorption energies of $\mathrm{CH}_{4}$ and DTAB on the surface of the coal molecular model were 2.15 and $42.69 \mathrm{~kJ} / \mathrm{mol}$, and the adsorption distances were 0.261 and $0.238 \mathrm{~nm}$, respectively. $\mathrm{O} 20-\mathrm{H} 84$, in the DTAB-coal configuration, had a larger Mulliken overlapping population than $\mathrm{O} 20-\mathrm{H} 49$ in the $\mathrm{CH}_{4}$-coal configuration. Our results confirmed that the DTAB-coal configuration was more stable than the $\mathrm{CH}_{4}$-coal configuration. When there was competitive adsorption between DTAB and $\mathrm{CH}_{4}$ on the surface of coal, the coal molecules preferentially adsorbed DTAB to reach a more stable state. The FTIR study results showed that the absorption peaks of hydroxyl and other oxygen-containing functional groups in the coal samples were inhibited after DTAB treatment. The adsorption capacity of the coal samples for methane decreased by $37.3 \%$ after the DTAB treatment. The calculated results were consistent with the experimental results. The calculated and experimental results showed that DTAB promoted gas desorption and prevented gas readsorption. In this paper, it was theoretically proven that DTAB binds more strongly to coal and can inhibit methane binding. This opens up the possibility of using DTAB in coal seam fracturing or wetting. 
Author Contributions: Data curation, J.G.; methodology, Y.T.; writing—original draft, S.L.; writing-review and editing, J.W. and S.G. All authors have read and agreed to the published version of the manuscript.

Funding: The authors gratefully acknowledge the financial support of the Applied Basic Research Programs of Shanxi Province, grant number 201801D121265, the Excellent Talents of Science and Technology Innovation Project, grant number 201601051499070, and the National Natural Science Foundation of China, grant number 51274116.

Acknowledgments: The authors wish to thank the co-workers and technical staff at the Taiyuan University of Technology (TYUT) who provided coal samples and laboratory equipment.

Conflicts of Interest: The authors declare no conflict of interest. The founding sponsors had no role in the design of the study; in the collection, analyses, or interpretation of data; in the writing of the manuscript; and in the decision to publish the results.

\section{References}

1. Brodny, J.; Tutak, M. Analysis of methane hazard conditions in mine headings. Tehn. Vjesn. 2018, 25, 271-276.

2. Krause, E.; Smoliński, A. Analysis and Assessment of Parameters Shaping Methane Hazard in Longwall Areas. J. Sustain. Min. 2013, 12,13-19. [CrossRef]

3. Tutak, M.; Brodny, J. Predicting Methane Concentration in Longwall Regions Using Artificial Neural Networks. Int. J. Environ. Res. Public Health 2019, 16, 1406. [CrossRef] [PubMed]

4. Yuan, L. Strategic thinking of simultaneous exploitation of coal and gas in deep mining. J. China Coal 2016, 41, 1-6.

5. Tutak, M.; Brodny, J. Forecasting Methane Emissions from Hard Coal Mines Including the Methane Drainage Process. Energies 2019, 12, 3840. [CrossRef]

6. Yao, S. Study on the Technology of Increasing Drainage in High Gas and Low Air Permeability Coal Seam. Master's Thesis, Anhui University of Science \& Technology, Huainan, China, 2005.

7. Lin, J.; Ren, T.; Cheng, Y.; Nemcik, J.; Wang, G. Cyclic N2 injection for enhanced coal seam gas recovery: A laboratory study. Energy 2019, 188, 116115. [CrossRef]

8. Aziz, N.; Black, D.; Ren, T. Keynote paper Mine gas drainage and outburst control in Australian underground coal mines. Procedia Eng. 2011, 26, 84-92. [CrossRef]

9. Lunarzewski, L. Gas Drainage Practices. In Proceedings of the Coal Operators' Conference, Wollongong, Australia, 15 February 2001.

10. Zhang, Q. Development and Current Situation of Study on Theory of Methane Adsorption on Coal. Procedia Earth Planet. Sci. 2011, 3, 318-324. [CrossRef]

11. Chen, C. Study on the Physical and Chemical Structure of Coal and Mechanism of Adsorption (Desorption) of Methane. Ph.D. Thesis, Chongqing University, Chongqing, China, 1995.

12. He, X.; Song, D.; Liu, X.; Wang, W.; Li, Z.; Liu, H. Micro electrical characteristics of coals with different metamorphic grade. J. China Coal Soc. 2018, 43, 5-13.

13. Crawford, R.; Mainwaring, D. The influence of surfactant adsorption on the surface characterisation of Australian coals. Fuel 2001, 80, 313-320. [CrossRef]

14. Orumwense, F.O. Estimation of the wettability of coal from contact angles using coagulants and flocculants. Fuel 1998, 77, 1107-1111. [CrossRef]

15. Wang, B.; li, M.; Zhao, Q.; Qin, Y.; Xie, K. Relation ship between surface potential and functional groups of coal. J. Chem. Ind. Eng. 2004, 55, 1329-1334.

16. Boethling, R.S.; Lynch, D.G. Quaternary Ammonium Surfactants. In Detergents; Springer: Berlin/Heidelberg, Germany, 1992; pp. 145-177.

17. Pashley, R.M.; McGuiggan, P.M.; Ninham, B.W.; Brady, J.; Evans, D.F. Direct measurements of surface forces between bilayers of double-chained quaternary ammonium acetate and bromide surfactants. J. Phys. Chem. 1986, 90, 1637-1642. [CrossRef]

18. Liu, Z.; Gao, R.; Dong, Z.; Li, X.; Zhao, J. Quaternary Ammonium Gemini Surfactants Used in Enhanced Oil Recovery: Synthesis, Properties, and Flooding Experiments. Tenside Surfactants Deterg. 2017, 54, $260-271$. [CrossRef]

19. Das, D.; Dash, U.; Meher, J.; Misra, P.K. Improving stability of concentrated coal-water slurry using mixture of a natural and synthetic surfactants. Fuel Process. Technol. 2013, 113, 41-51. [CrossRef]

20. Hassas, B.V.; Karakaş, F.; Çelik, M.S. Ultrafine coal dewatering: Relationship between hydrophilic lipophilic balance (HLB) of surfactants and coal rank. Int. J. Miner. Process. 2014, 133, 97-104. [CrossRef] 
21. Singh, B.P. The role of surfactant adsorption in the improved dewatering of fine coal. Fuel 1999, 78, 501-506. [CrossRef]

22. Kumar, S.; Mandal, A. Studies on interfacial behavior and wettability change phenomena by ionic and nonionic surfactants in presence of alkalis and salt for enhanced oil recovery. Appl. Surf. Sci. 2016, 372, 42-51. [CrossRef]

23. Li, Z.; Gallus, L. Adsorption of dodecyl trimethylammonium and hexadecyl trimethylammonium onto kaolinite-Competitive adsorption and chain length effect. Appl. Clay Sci. 2007, 35, 250-257. [CrossRef]

24. Nakada, K.; Ishii, A. Migration of adatom adsorption on graphene using DFT calculation. Solid State Commun. 2011, 151, 13-16. [CrossRef]

25. Wang, H.; Zhong, C.; Ma, Q.; Ma, J.; He, H. The adsorption and oxidation of SO2 on MgO surface: Experimental and DFT calculation studies. Environ. Sci. Nano 2020, 7, 1092-1101. [CrossRef]

26. Marzec, A. Towards an understanding of the coal structure: A review. Fuel Process. Technol. 2002, 77, 25-32. [CrossRef]

27. Krzesińska, M. Coal structure studied by means of molecular acoustics methods. Fuel Process. Technol. 2002, 77, 33-43. [CrossRef]

28. Mathews, J.P.; Chaffee, A.L. The molecular representations of coal-A review. Fuel 2012, 96, 1-14. [CrossRef]

29. Wiser, W.H. Conversion of Bituminous Coal to Liquids and Gases: Chemistry and Representative Processes. Magn. Reson. 1984, 325-350.

30. Tang, Y.; Li, Z.; Ma, D.; Ji, H. Low-Temperature Oxidation Properties of Carboxyl in Coal Based on Model Compound of Spontaneous Combustion of Coal. Asian J. Chem. 2013, 25, 8660-8662. [CrossRef]

31. Tang, Y.; Li, Z.; Yang, Y.; Song, N.; Ma, D. Oxidation Experiment of Coal Spontaneous Combustion Model Compounds. Asian J. Chem. 2013, 25, 441-446. [CrossRef]

32. Marzec, A. Macromolecular and molecular structure of coal and the possible role of pyrolysis-field desorption mass spectrometry in its elucidation. J. Anal. Appl. Pyrolysis 1985, 8, 241-254. [CrossRef]

33. Chen, C.G.; Gu, M.; Xian, X.F. Study on structure of coal and adsorption mechanism of methane on it. Coal Convers. 2003, 26, 5-9.

34. Feng, Z.; Zhou, N.; Zhao, Y.; Cai, T. Study on microstructural changes of coal after methane adsorption. J. Nat. Gas Sci. Eng. 2016, 30, 28-37. [CrossRef]

35. Thierfelder, C.; Witte, M.; Blankenburg, S.; Rauls, E.; Schmidt, W.G. Methane adsorption on graphene from first principles including dispersion interaction. Surf. Sci. 2011, 605, 746-749. [CrossRef]

36. Carbó-Dorca, R.; Bultinck, P. Quantum Mechanical Basis for Mulliken Population Analysis. J. Math. Chem. 2004, 36, 231-239. [CrossRef]

37. Dobson, J.; Hinchliffe, A. Mulliken population analysis and quantum mechanical probability. J. Mol. Struct. 1975, 27, 161-166. [CrossRef]

38. Mavor, M.; Owen, L.; Pratt, T. Measurement and Evaluation of Coal Sorption Isotherm Data. In Proceedings of the SPE Annual Technical Conference and Exhibition. Society of Petroleum Engineers, New Orleans, LA, USA, 23-26 September 1990.

39. Moffat, D.H.; Weale, K.E. Sorption by coal of methane at high pressure. Fuel 1955, 34, 449-462.

(C) 2020 by the authors. Licensee MDPI, Basel, Switzerland. This article is an open access article distributed under the terms and conditions of the Creative Commons Attribution (CC BY) license (http://creativecommons.org/licenses/by/4.0/). 